Ryan F. Slocum, Herbert L. Jones, Matthew T. Fletcher, Brandon M. McConnell, Thom J. Hodgson, Javad Taheri, and James R. Wilson. 2020. Improving Chemotherapy Infusion Operations through the Simulation of Scheduling Heuristics: a case study. Health Systems, Vol 10, No 8, 163-178, https://doi.org/10.1080/20476965.2019.1709908.

\title{
Improving Chemotherapy Infusion Operations through the Simulation of Scheduling Heuristics: a case study
}

\author{
Ryan F. Slocum ${ }^{\mathrm{a}}$ and Herbert L. Jones ${ }^{\mathrm{b}}$ (D) and Matthew T. Fletcher ${ }^{\mathrm{c}}$ (D)and \\ Brandon M. McConnell ${ }^{\mathrm{c}}$ (D) and Thom J. Hodgson ${ }^{\mathrm{b}}$ (D) and Javad Taheri ${ }^{\mathrm{b}}$ and James \\ R. Wilson ${ }^{\mathrm{b}}$ \\ ${ }^{a}$ United States Army; \\ ${ }^{\mathrm{b}}$ Department of Industrial \& Systems Engineering; North Carolina State University; \\ Raleigh, NC; \\ ${ }^{\mathrm{c}}$ Center for Additive Manufacturing and Logistics; North Carolina State University; \\ Raleigh, NC.
}

\section{ARTICLE HISTORY \\ Compiled February 28, 2020}

\begin{abstract}
Over the last decade, the healthcare industry has experienced a substantial shift from inpatient care to outpatient services as the ability to provide timely, safe outpatient care has increased. There has been a dramatic movement away from inpatient chemotherapy treatments, such that nearly $90 \%$ of all infusions are now administered outpatient. This shift has challenged oncology clinics to make chemotherapy treatment as widely available as possible, while attempting to treat all patients within a fixed period of time. Historical data from a Veterans Affairs chemotherapy clinic in the United States supplemented with staff input informed the development of a discrete event simulation model of the clinic. The simulation study examines the impact of altering the current schedule, where all patients arrive at 8:00 AM, to a schedule that assigned patients to two or three different appointment times based on the expected length of their chemotherapy infusion. The results identify multiple scheduling policies that could be easily implemented at the Durham, North Carolina, U.S.A., Veterans Administration Medical Center chemotherapy clinic with the best solutions reducing average patient waiting time by $24 \%$ and reducing average nurse overtime by $66 \%$.
\end{abstract}

\section{KEYWORDS}

discrete event simulation (DES); scheduling; healthcare; chemotherapy

\section{Introduction}

\subsection{Background}

In 1930, the United States (U.S.) Congress authorized the President to establish the Veteran's Administration (VA) in order to provide care for the men and women who served in the U.S. military (Slocum, 2014; U.S. Department of Veterans Affairs, 2018b, 2018c). While the VA provides a wide range of services to veterans nationwide, its healthcare system is arguably the most important and most costly service. Since its creation, the VA healthcare system has expanded from 54 hospitals to 153 hospitals, 
909 community based outpatient clinics, and 135 nursing home clinics. VA Medical Centers (VAMCs) provide full spectrum services, ranging from routine outpatient services to emergency care to specialized services such as oncology, neurology, and prosthetics. Often, VA hospitals are located adjacent to medical schools, allowing experienced physicians to provide excellent care to veterans while training the next generation of medical providers.

Our focus is on improving scheduling for the outpatient chemotherapy clinic at the U.S. Veteran's Affairs Medical Center in Durham, North Carolina, which provides care to over 200,000 veterans across 26 counties in the state of North Carolina (U.S. Department of Veterans Affairs, 2018a). However, since not all VAMCs are capable of providing oncology services, the Durham VAMC treats patients from states in the region, with patients often traveling from northern South Carolina, southern Virginia, and as far east as the North Carolina coastal counties.

The chemotherapy clinic is open 250 days a year and administered more than 3,500 doses of chemotherapy in 2013. The clinic is staffed with five chemotherapy certified nurses that cycle patients through 14 infusion chairs throughout the day. The clinic administers over 80 different chemotherapy regimens (regimens refer to the combination of one or more drugs) and provides ancillary services such as phlebotomies and blood transfusions. While some treatments take 15 minutes, others take upwards of six to eight hours - yet in each case, the patient is told to arrive at 8:00 AM for treatment. This practice has resulted in very long wait times for the patients and significant overtime hours for the nursing staff.

\subsection{Clinic Overview}

The daily process for the chemotherapy clinic consists of three major phases: (1) lab work, (2) pharmacy processing, and (3) chemotherapy infusion. When patients arrive to the clinic, their first stop is the phlebotomy station. The phlebotomy station is staffed with two phlebotomists, one arriving at 6:00 AM and the other arriving at 7:30 AM. Patients are called in to the phlebotomy station on a first come, first served (FCFS) basis. The phlebotomist draws multiple blood samples, which are then escorted to the hospital's main lab. Lab tests are required because providers must ensure their patients can safely receive chemotherapy. Chemotherapy drugs are fundamentally toxic to the body and typically work by either destroying cells or preventing cell replication. The drugs are unable to differentiate between good cells and cancer cells, which are both affected during chemotherapy treatments, so lab tests are essential for determining whether a patient can withstand their next round of treatment. Once the main lab completes the testing, the patient's doctor will review the results to ensure the patient can tolerate treatment. If the patient is healthy enough for treatment, the doctor will notify the attending nurse to submit the patient's chemotherapy order to the pharmacy. If the patient is not a viable candidate for treatment, the doctor will either postpone treatment to a later date or they may supplement the patient with a blood transfusion, platelets, etc.

Unlike many VAMCs, the Durham clinic has a dedicated pharmacy located next to the infusion clinic. The pharmacy is staffed with two pharmacists who rotate between working in the hospital's main pharmacy and the chemotherapy pharmacy. The pharmacy operates as two single server processes in series. The order starts with one pharmacist entering all of the patient and order information and printing out drug labels. Once data entry is complete, the second pharmacist will gather all of the neces- 
sary supplies to mix the drug in the neighboring clean room under a ventilation hood. Once the drug has been prepared, the pharmacy delivers the chemotherapy drugs to the infusion clinic. The pharmacy processes drug orders on a FCFS basis, unless one of the nurses asks the pharmacists to bump an order to the front of the line (typically for patients with very long infusion times).

While the nurses wait for their patients' lab results and chemotherapy drugs from the pharmacy, they collect vital signs and administer chemotherapy premedication drugs, which must be taken at least 30 minutes prior to starting an infusion. Once the nurses receive their patients' chemotherapy drugs, the process is fairly deterministic since they are pumped in to the patients' blood stream at a predetermined rate. Occasionally patients experience adverse reactions to the chemotherapy drugs, which can delay or prematurely end a treatment, but these instances are very rare.

VAMCs are at a significant disadvantage when it comes to controlling their patient flow. In many cases, patients rely on VA sponsored buses to get to the hospital and unlike most community hospitals, some patients will be traveling over three hours for their appointment. As a result, VAMCs are reluctant to enforce strict adherence to appointment times and will generally do everything in their power to treat patients whenever they arrive. However, by telling every patient to arrive at 8:00 AM the chemotherapy clinic cannot effectively control the order in which patients are treated.

When every patient is scheduled to arrive at 8:00 AM, the clinic ensures the lab, pharmacy, and nursing staff will be fully utilized in the morning and the staff rarely waits on patients to arrive; however, patients spend significantly more time in the system waiting for service. Furthermore, this is not necessarily the most efficient scheduling method as it creates a longer queue at the phlebotomy station, which may delay lab results for certain patients. When patients with short infusions get their lab results ahead of those patients with long infusions, the pharmacy builds a backlog of orders that are tail heavy with long infusions. Now, instead of starting a five-hour infusion at $10 \mathrm{AM}$, the nurses might not be able to start the infusion until $12 \mathrm{PM}$.

As a population of patients, veterans with cancer are one of the last demographics that should spend hours waiting for service. The goal of this project was to build a simulation of the clinic to examine how various scheduling heuristics affected the average waiting time in the system (measured from the time a patient checks in until the patient starts their chemotherapy infusion) and the clinic's annual overtime cost. The first step was to build a simulation that accurately models the current system where every patient was told to arrive at $8 \mathrm{AM}$. The simulation uses a combination of historical data and anecdotal evidence from the clinic's staff to model various process times. A collaborative effort from the nursing staff, pharmacy, and doctors verified that the system is modeled correctly, and historical overtime data served to validate the simulation's construction. Once the base schedule simulation was built, the study examined the impact of each proposed schedule against the current schedule.

The rest of this paper is organized as follows: Section 2 discusses relevant literature, Section 3 presents the simulation model, Section 4 summarizes key results from the appointment policies, and Section 5 provides some final thoughts. 


\section{Literature Review}

\subsection{Discrete Event Simulation in Healthcare}

Much of the discrete event simulation (DES) literature in healthcare focuses on emergency departments (ED). These studies often include patient-centric performance measures such as waiting time or length of stay along with provider-focused metrics like resource utilization and productivity (Abo-Hamad \& Arisha, 2013). Several studies present DES-based decision support systems to improve management of emergency departments (Ordu, Demir, \& Fofallis, 2019), especially under strained or capacity constrained conditions (Kadri, Chaabane, \& Tahon, 2014).

These studies cover geographically diverse clinics of varying scales including highvolume facilities (Oh, Novotny, Carter, Ready, \& Campbell, 2016). Gul, Guneri, and Gunal (2019) present a case study for managing a network of EDs from five public hospitals in Istanbul, Turkey, to evaluate preparedness for earthquakes. The interested reader should consult Gul and Guneri (2015) for a recent survey of ED simulation studies for normal and disaster conditions.

DES has also supported analysis and management of optometry clinics (Seminelli, Wilson, \& McConnell, 2016) and retinal services (Demir, Southern, Verner, \& Amoaku, 2018), as well as specialized cancer treatment clinics administering radiation (Babashov et al., 2017).

In a related study, Rohleder, Lewkonia, Bischak, Duffy, and Hendijani (2011) use DES to improve patient waiting time at an outpatient orthopedic clinic seeing 50 100 patients per day, most of whom have scheduled appointments throughout the day which differs from our study. Another closely related study is Richardson and Cohn (2018) which uses DES to understand the impact of make-ahead chemotherapy drug policies. Unlike Richardson and Cohn (2018), the case study in this paper centers on appointment block scheduling schemes to shape demand at a VA clinic.

\subsection{General Scheduling}

Nearly $90 \%$ of all oncology patients will be treated in an ambulatory (outpatient) setting over the course of their battle with cancer, which is why many professionals in the oncology and hematology field have realized a need for improved efficiency (Williamson, 2008). Although some outpatient clinics operate twenty-four hours a day, most mirror normal business hours, which presents the challenge of treating every patient within a limited period of time. Unlike the inpatient setting, outpatient nurses cannot pass their patient off to the next shift. Most infusion clinics tend to front load all of their appointments in an effort to reduce overtime hours, but this can result in long wait times for patients. Studies show that cancer patients tend to value quality of care above all other factors; excessive waiting times have become the most prevalent source of dissatisfaction (Thomas, Glynne-Jones, \& Chait, 1997). However, quality of care and excessive wait times are not a zero sum game, which is why many researchers are attempting to find ways to improve outpatient chemotherapy scheduling techniques.

The primary goal for chemotherapy clinics is to maximize the utilization of its infusion chairs so that the clinic can treat as many patients as possible in a single day without exceeding normal business hours. The current policy at the Durham VA clinic is an example of the simplest block scheduling technique. In this case, the number of blocks, $k$, equals 1 , and the number of patients assigned to that block, $n$, is equal to the total number of patients scheduled on that day. This technique is designed to minimize 
the service providers' idle times, but it typically comes at the expense of the patient whom experiences longer waiting times for service (Gupta \& Denton, 2008). The other end of the spectrum regarding block scheduling is to set the number of blocks equal to the number of patients, such that $k=n$, and the length of time allocated to each block $k$ is equal to the expected mean service time for each $n$ (Welch \& Bailey, 1952). This type of schedule has several drawbacks, primarily that it works best for a single server process (which the chemotherapy clinic is not), and its complexity can be very challenging for schedulers to execute.

A common practice for primary care doctors is to use a multiple-block/fixed interval rule (Cayirli \& Veral, 2003). Using this rule, clinics assign multiple patients identical appointment times, which are spread out across equal intervals throughout the day. For example, three patients could be assigned appointment times at 8:30 AM, and three more patients would be assigned appointments at 9:00 AM. This works particularly well in primary care or general practice settings because the mean service time is usually small (less than 15 minutes), but the wide range of chemotherapy infusion times may prohibit chemotherapy clinics from using fixed intervals.

\subsection{Chemotherapy Scheduling}

Few outpatient services in the healthcare field are as complex as the delivery of chemotherapy because there are multiple ancillary processes that work together before a patient can start their treatment. Depending on the processing capacity and variability of those ancillary services (phlebotomists, lab technicians, and pharmacists), it can be extremely difficult to develop an accurate appointment system. Some clinics encourage pre-infusion appointments, allowing the providers to review lab results 24-48 hours prior to a patient's chemotherapy infusion, thereby eliminating the uncertainty of those processes, but this is not practical for VA hospitals since many of their patients travel a great distance for treatment. Much of the reviewed literature focused exclusively on the infusion phase of outpatient chemotherapy clinics, which is a significant simplification because it eliminates the uncertainty, variability, and delays of the lab and pharmacy phases (Chabot \& Fox, 2005, Delaney, Jalaludin, Moylan, \& Barton, 2002; Hesaraki, Dellaert, \& de Kok, 2019; Turkcan, Zeng, \& Lawley, 2012).

One of the most significant advances in chemotherapy scheduling was the development of a meaningful patient classification system: Chabot and Fox (2005) develop acuity levels that represent a combination of the total amount of treatment time and the nursing attention each patient would require based on their prescribed chemotherapy regimen, where the acuity value $(1,2, \ldots, \kappa)$ was equal to the total treatment time divided by thirty minutes. Patients were scheduled using a multiple-block/variable interval system, with each nurse treated as a single-server and intervals were blocked off according to patient acuity levels. Chabot and Fox (2005) recognize that acuity levels did not eliminate the complexities involved in scheduling chemotherapy patients, but if clinics included acuity levels during the scheduling process, they would be able to better quantify a nurse's workload.

Turkcan et al. (2012) builds on Chabot and Fox (2005) by developing algorithms and heuristics in a 2-stage integer program to minimize patient treatment delays and staff overtime, while maximizing staff utilization. In order to balance nurse workloads, the integer program includes each patient's acuity level and for each nurse, the sum of their patient's total acuity was required to be less than or equal to a predetermined value. While this study provides the most detailed analysis of chemotherapy opera- 
tions, yielding one of the best optimization methodologies in its field, it only examines the infusion phase of the outpatient chemotherapy treatment process. Without addressing the lab and pharmacy phases, this planning and scheduling model cannot be implemented.

There are a number of outpatient chemotherapy DES studies in the literature (Ahmed, ElMekkawy, \& Bates, 2011; Alvarado, Cotton, Ntaimo, Pérez, \& Carpentier 2018; Liang, Turkcan, Ceyhan, \& Stuart, 2015; Woodall, Gosselin, Boswell, Murr, \& Denton, 2013; Yokouchi, Aoki, Sang, Zhao, \& Takakuwa, 2012). Liang et al. (2015) use both DES and an optimization model to improve patient flow and scheduling in an outpatient chemotherapy clinic, but these studies consider a clinic where appointments are spread through the day, with $45 \%$ of appointments requiring no chemotherapy at all. While the study considers multiple patient classes and routings in a multi-facility setting, it is not directly applicable to the Durham VAMC. Yokouchi et al. (2012) also suggests an appointment scheduling system based on infusion times but stop short of providing a heuristic scheduling rule. A few studies suggest ordering patients by decreasing infusion time is a good target sequence (Garaix, Rostami, \& Xie, 2018; Suss, Bhuiyan, Demirli, \& Batist, 2017), though Garaix et al. (2018) is limited by strong assumptions such as "the pharmacy is not a bottleneck and drugs arrive on time," there is no idle time in an oncologist's schedule, and all patients arrive on time.

Of the few studies that have reached implementation and tested their algorithms or models, most are too specific to a particular clinic or hospital, thus their findings cannot be replicated elsewhere (Belter et al., 2012; Hendershot et al., 2005; Kallen, Terrell, Lewis-Patterson, \& Hwang, 2012). Several clinics have attempted to create fast-tracking programs that assign a higher priority to patients with shorter infusion times or patients that require minimal nursing attention. These are logical strategies; however, their success is entirely dependent on pharmacy capacity, and neither of the studies discuss how to best schedule these appointments.

Eisenburg (2009) highlights a common issue with many outpatient chemotherapy deliver systems, which is particularly evident at the Durham VAMC: nurses are involved in the scheduling appointments. Instead of focusing solely on providing care, some nurses have an active role establishing appointments and balancing their patient load. But when nurses manage appointments independently, clinics lose the ability to control patient flow through the system.

The volume of existing research regarding outpatient chemotherapy scheduling demonstrates the significant need for improvement, yet the vast majority of the research results cannot be implemented due to either an oversimplification of the problem or the complexity of the model. The few studies that reached implementation were generally designed for a specific subset of patients or the system required a resource capacity that could not be widely replicated. A simple and easy-to-implement heuristic that clinics could use as a guideline for scheduling chemotherapy appointments would be an invaluable tool.

\section{Simulation Model}

\subsection{Model Definition}

Patients move through the Durham VAMC chemotherapy clinic processes according to Figure 1. In the model, the only entities in the system are the patients. The number of patients that enter the clinic varies from day to day, as does the type of chemotherapy 


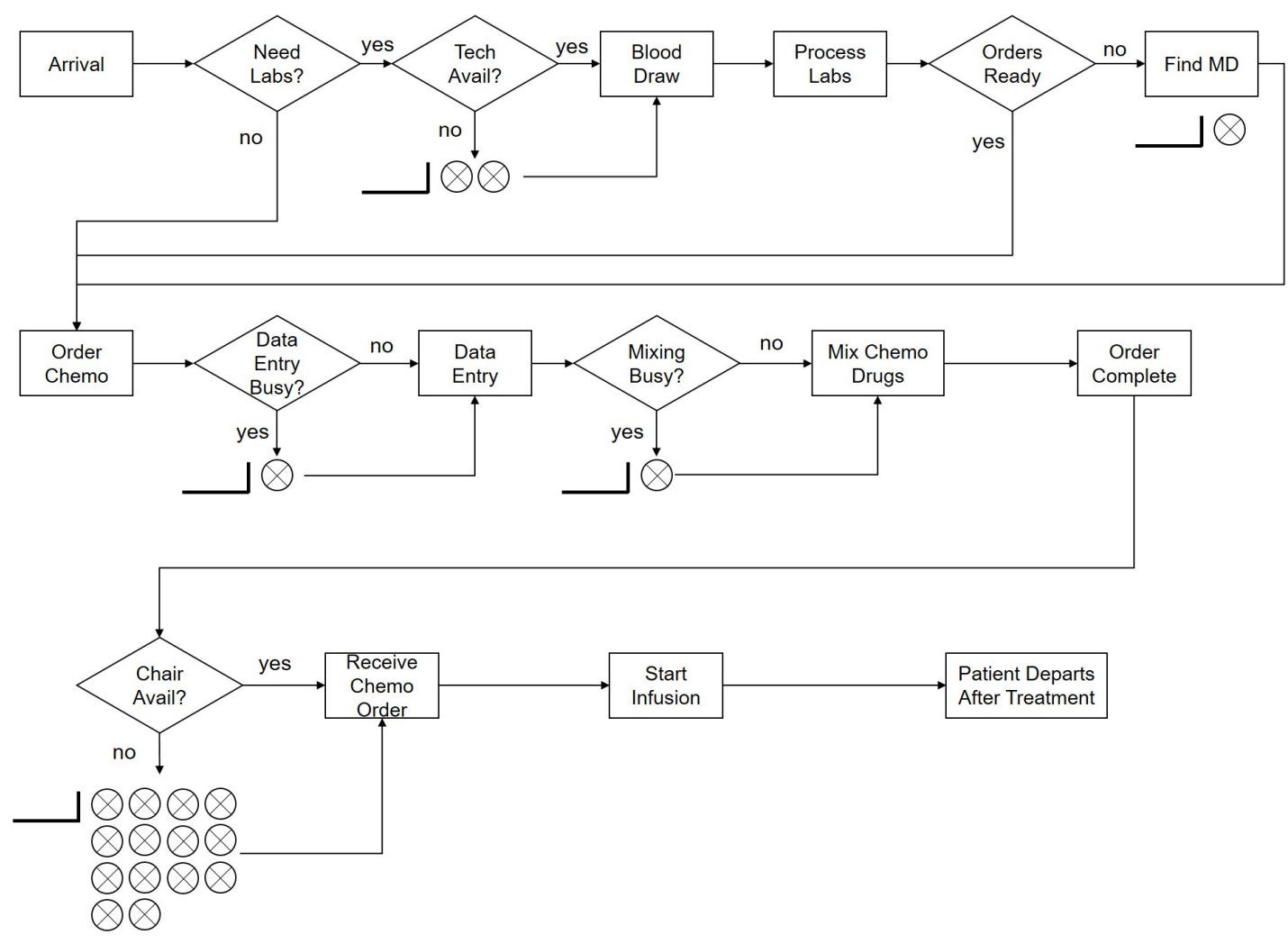

Figure 1. Infusion Clinic Patient Flow Diagram (does not include rare events such as unfavorable lab results or adverse reactions to infusions).

regimens administered. The attributes that characterize each unique patient are: (1) Arrival Time and (2) Chemotherapy Regimen. Both of these attributes are sampled from an appropriate distribution, which will be discussed in the sections below. Next, there are several sub-attributes that characterize a patient's treatment requirements based on his/her chemotherapy regimen: (1) Appointment Time, (2) Infusion Length, (3) Labs required prior to infusion, and (4) Probability of needing labs. Under the current system, every patient's appointment time was 8:00 AM.

The processes for this model are listed below and their corresponding processing times will be discussed in the following sections:

- Patient Arrivals,

- Blood Draw,

- Lab Processing,

- Wait on Chemotherapy Orders,

- Data Entry,

- Mix Chemotherapy Drugs, and

- Chemotherapy Infusion.

The resources for this model and their associated capacities are listed in Table 1 Notice that the lab process does not have an assigned resource because the clinic does not have the ability to process labs internally. Instead, lab processing times are modeled purely as a delay rather than a process that seizes a resource during its delay. Similarly, the process of waiting on chemotherapy orders is modeled purely as a delay. 
Table 1. Clinic Resources

\begin{tabular}{ll}
\hline Resource Capacity & Capacity \\
\hline Phlebotomist & $1-2$ \\
Data Entry Pharmacist & 1 \\
Mixing Pharmacist & 1 \\
Nurse & $3-4$ \\
\hline
\end{tabular}

\subsection{Patient Arrivals}

Although every patient is scheduled for an 8:00 AM appointment, the daily variance in arrival times is significant. Some patients try to game the system, knowing that if they show up early they can be the first patient in the queue, whereas other patients are indifferent to their arrival time because they know that their infusion will be an allday event. It is difficult to quantify the impact of these beliefs or to account for them in a simulation, and it is probably unrealistic to assume patients would display the same behavior if the clinic used a meaningful appointment system. However, without having data to the contrary, all simulations follow the same arrival time distribution, regardless of the appointment time.

To model the patient arrival times, the simulation uses historical check-in times from the patients at the clinic. The earliest arrival time from the sample data is 6:30 $\mathrm{AM}$ and the latest is 10:20 AM. However, there are only two patients who arrived after 10:00 AM and occasionally nurses tell their patients with shorter infusions to come later in the morning. Since these two data points are significant outliers (60 minutes greater than the next latest arrival time), it is reasonable to assume that these patients were not instructed to arrive at 8:00 AM, therefore they are excluded from the sample population.

The rest of the data points are scaled by subtracting the sample time from 6:30 AM, where 6:30 AM is the earliest data point in the set. This step converts each data point from a time to the number of minutes it is from the lower bound (6:30 AM).

Based on historical arrival times, we model each patient's arrival time as an independent and identical sample from a generalized Beta distribution of the form $a+(b-a) \times \operatorname{Beta}\left(\alpha_{1}, \alpha_{2}\right)$ with lowerbound $a$, upperbound $b$, and shape parameters $\alpha_{1}, \alpha_{2}$ (Kuhl et al., 2010). Our best fit resulted in an arrival time distribution modeled by 6:30 AM $+168 \times \operatorname{Beta}(3.64,3.35)$ minutes. Goodness of fit tests and sensitivity analysis for this choice (and others in this paper) may be found in Slocum (2014).

\subsection{Patient Distribution}

In looking at the average number of patients that visited the chemotherapy clinic, a strong correlation emerges between the number of nurses scheduled to work on a given day and the number of patients that were treated. As summarized in Table 2 historical data from January-October 2013 revealed that $82.7 \%$ of the time there were four nurses on the schedule and $17.3 \%$ of the time there were 3 nurses on the schedule. There were three instances when the clinic operated with two nurses; however those days were limited to the 2nd, 3rd, and 4th of January, therefore they were excluded from the sample population.

The number of patients who received treatment at the clinic when there are 3 
Table 2. Patients treated each day based on number of nurses.

\begin{tabular}{llll}
\hline Nurses & Probability & Average Number Patients Treated & Standard Deviation \\
\hline 3 & $17.3 \%$ & 12.1 & 2.2 \\
4 & $82.7 \%$ & 14.7 & 2.7 \\
\hline
\end{tabular}

nurses on the schedule is significantly different than the number of patients who are treated when there are four nurses on the schedule. Based on historical data which included lower and upper bounds, we model the number of patients treated each day, NumPatients, according to

$$
\text { NumPatients }= \begin{cases}\operatorname{INT}(7+11 \times \operatorname{Beta}(2.42,2.85)) & 3 \text { nurses scheduled } \\ \operatorname{INT}(7.5+14 \times \operatorname{Beta}(3.21,2.97)) & 4 \text { nurses scheduled }\end{cases}
$$

where $\operatorname{INT}(\cdot)$ rounds to the nearest integer value.

\subsection{Phlebotomy Station}

The phlebotomy station is the first queue that patients enter when they arrive to the clinic. The clinic has two phelobomists and under the current schedule, one works from 6:00 AM until 2:00 PM and the other works from 7:30 AM until 3:30 PM.

The average amount of time required to draw a patient's blood is 5 minutes, although some patients' veins are more challenging than others, in which case a phlebotomist could spend up to 10 minutes trying to access a vein. After 10 minutes of trying to find a vein, the phlebotomist typically directs the patient to the infusion room where a specialist will come to draw their blood.

The difficulty in modeling the phlebotomy station is that chemotherapy patients represent less than half of the patients that come through the station each day. Hematology and oncology patients that are scheduled to meet with their doctor also use the clinic's phlebotomy station, and chemotherapy patients are not given priority. From personal observations, there are rarely two phlebotomists in the office at the same time, as one is either absent, on break, or completing administrative work instead of drawing blood samples.

The simulation assumes a constant service time of 10 minutes throughout the day, which is double the average service time during these periods. Sensitivity analysis shows the results are insensitive to this assumption (Slocum, 2014). By using a service time of double the average service time, the model attempts to account for the impact non-chemotherapy patients would have on the phlebotomy queue length and waiting time.

\subsection{Lab Results}

Each chemotherapy regimen attacks cancer cells differently, but the general concept is that chemotherapy drugs work by killing cells during a specific phase of the cell cycle and are unable to differentiate between good cells and cancer cells. Therefore, doctors require lab tests to determine whether a patient can withstand their next round of chemotherapy. The most common tests prior to receiving chemotherapy are 
complete blood count (CBC) tests and chemistry (Chem-7) tests. CBC tests measure a patient's ability to recover from an infection or blood loss, while the Chem-7 tests indicates whether a patient's metabolism will be able to clear the chemotherapy drugs adequately.

At the VA, over $95 \%$ of the regimens required both of these tests. Historically, nurses found the Chem-7 test results generally take longer to receive than the CBC test results. Without access to historical lab result times, the simulation estimated the lab result waiting times with a Beta distribution using the method detailed in Kuhl et al. (2010) and presented below. Define $T_{L a b}$ as the time in minutes to receive lab results. Anecdotal evidence from the nursing staff suggests that the fastest they can get both test results is 45 minutes $(a)$, the mode $(m)$ is 70 minutes, and the longest amount of time they have waited is 150 minutes $(b)$. The nurses also believe the average time they spend waiting for lab results is 75 minutes $\left(E\left[T_{L a b}\right]\right)$. Using this information, we derive the shape parameters for the generalized Beta distributions below. Let $a=45, m=70, b=150$, and $\mu=\mathrm{E}\left[T_{L a b}\right]=75$ minutes; solving

$$
\begin{gathered}
\frac{\left(\alpha_{1}-1\right) b+\left(\alpha_{2}-1\right) a}{\alpha_{1}+\alpha_{2}-2}=m \\
\frac{\alpha_{1} b+\alpha_{2} a}{\alpha_{1}+\alpha_{2}}=\mu
\end{gathered}
$$

yields $\alpha_{1}=3.143$ and $\alpha_{2}=7.857$ resulting in

$$
T_{L a b} \sim 45+105 \times \operatorname{Beta}(3.143,7.857) .
$$

\subsection{Chemotherapy Orders}

Occasionally, a patient's lab results will be ready but the nursing staff does not have chemotherapy orders to give the pharmacy. When this happens, the nurse has to locate the patient's provider and ask them for chemotherapy orders. VA hospitals have not switched to electronic orders, thus the doctor must provide hard copy orders for every patient. This can be particularly challenging at the Durham VA hospital, because often times its oncologists spend several days each week at the Duke University Hospital.

The frequency of these delays is unclear, therefore the simulation uses anecdotal evidence to capture the process. According to the nursing staff, they have to track down orders for $25 \%$ of their patients. The lower bound for this delay is zero minutes, since it is possible for the doctor to deliver orders simultaneously with the lab results. The nurses agreed that the mode is roughly 10 minutes and the upper bound is 120 minutes; however, the most common waiting time is 20 minutes. The time to locate chemotherapy orders is

$$
T_{\text {Locate }} \sim 120 \times \operatorname{Beta}(1.6667,8.3333) .
$$

\subsection{Pharmacy Process}

The pharmacy operates as two single server queues in series, where the first stage is the data entry phase and the second stage is the mixing phase. The chemotherapy 
clinic does not have two dedicated pharmacists, rather the hospital rotates its 14-16 pharmacists between the main pharmacy and the chemotherapy pharmacy to ensure all of their employees are capable of supporting either assignment and to limit the amount of exposure the pharmacists have to potentially harmful drugs.

Typically, the senior pharmacist in the chemotherapy room is responsible for the data entry portion of the process because it requires significant attention to detail and if the pharmacy makes a mistake, it usually occurs during data entry. For this simulation, the data entry phase refers to the time interval starting when the pharmacy receives the order until the time the mixing pharmacist enters the clean room to mix the drugs. During this phase, the pharmacist reviews the order and dosage calculations, enters the patient information, enters the drug data, and prepares a layout of drugs and mixing solutions. Once all of this is complete, both pharmacists review the layout together to verify that the order is correct - this ends the data entry phase. Typically, this process takes approximately 20 minutes, with a lower bound of 15 minutes and an upper bound of 25 minutes. This process is modeled with the following Beta distribution:

$$
T_{\text {Data }} \sim 15+10 \times \operatorname{Beta}(4,4) .
$$

The next phase is the mixing phase, which begins when the mixing pharmacist enters the clean room. The mixing pharmacist carries all of the drugs to the ventilation hood and proceeds to mix all of the drug orders under the hood thereby reducing their exposure to the drugs. While some of the drugs take longer to dissolve in the saline solution than others, this process takes approximately 15 minutes, with a lower bound of 5 minutes and an upper bound of 25 minutes. It is modeled with the Beta distribution below:

$$
T_{\text {Mix }} \sim 5+20 \times \operatorname{Beta}(4,4) .
$$

\subsection{Chemotherapy Regimen Data}

Initially, one may think that the type of cancer, whether it be colon, lung, or pancreatic would be important to the simulation, but it turns out to be largely irrelevant. Instead, knowing which treatment regimen a patient is on provides much more useful information, because the regimen dictates the expected infusion length, probability of needing labs, and determines which labs are required prior to treatment.

One of the ways the simulation attempts to schedule patients is based on the expected length of their infusion. The simulation breaks the various infusions lengths into four categories: Quick, Short, Intermediate, and Long. A quick infusion is one that requires less than 1 hour of chair time. Quick infusions account for $49.3 \%$ of all infusions. A short infusion is one that takes between 1 and 2 hours. Short infusions account for $21.4 \%$ of all infusions. Intermediate infusions are those that take between 2 and 4 hours, and account for $18 \%$ of all infusions. Long infusions are those that take greater than 4 hours to administer and they account for $11.3 \%$ of all infusions.

The type of chemotherapy regimen that a patient is prescribed dictates the probability of needing labs when they arrive for treatment. Although labs are required prior to any patient receiving chemotherapy, labs are only required on the first day of treatment for patients receiving multiday infusions. For example, a patient that is on the 
Table 3. Empirical Infusion Distribution based on 1829 patient appointments from 1 January - 1 July 2013. Note: PMF: probability mass function; CDF: cumulative distribution function.

\begin{tabular}{|c|c|c|c|c|c|c|c|c|c|c|c|}
\hline PMF & $\mathrm{CDF}$ & Regimen & Count & PMF & $\mathrm{CDF}$ & Regimen & Count & PMF & $\mathrm{CDF}$ & Regimen & Count \\
\hline 0.000547 & 0.000547 & $0.45 \mathrm{NSS}$ & 1 & 0.007108 & 0.315473 & CISPLATIN & 13 & 0.000547 & 0.632586 & Magnesium 1 gram & \\
\hline 0.002734 & 0.00328 & 0.9 NSS & 5 & 0.022963 & 0.338436 & CISPLATIN $>75 \mathrm{MG} / \mathrm{M} 2$ & 42 & 0.011482 & 0.644068 & OXALI/BEVAC & 21 \\
\hline 0.002734 & 0.006014 & 1 UNIT BLOOD & 5 & 0.00328 & 0.341717 & CYCLO/DOXOR & 6 & 0.018589 & 0.662657 & OXALI/BEVAC 1st dose & 34 \\
\hline & 0.026791 & 2 UNITS BLOOD & 38 & 0.014215 & 0.355932 & CYCLO/VELC & 26 & 0.032258 & 0.694915 & OXALIPLATIN & 59 \\
\hline 0.002187 & 0.028978 & 2 UNITS BLOOD + PLATELET & 4 & 0.031711 & 0.387644 & DECITABINE & 58 & 0.004374 & 0.699289 & PACLI/CARBO & \\
\hline 0.00164 & 0.030618 & 5 -FU & 3 & 0.002187 & 0.389831 & DOCET/HERCE/PETUZ & 4 & 0.00164 & 0.700929 & PACLITAXEL & 3 \\
\hline 0.015856 & 0.046473 & ABVD & 29 & 0.006561 & 0.396391 & DOCET/ZOMET & 12 & 0.004921 & 0.70585 & PAMIDRONATE $>60 \mathrm{~mm}$ & 9 \\
\hline 0.004921 & 0.051394 & ADO-TRASTUZUMAB EMTANSINE & 9 & 0.030618 & 0.427009 & DOCETAXEL & 56 & 0.004921 & 0.710771 & PANIT/IRINO & 9 \\
\hline 0.055768 & 0.107162 & Ancillary Therapy & 102 & 0.00164 & 0.42865 & DOXORUBICIN HCL & 3 & 0.001093 & 0.711864 & PANITUMUMAB & 2 \\
\hline 0.018589 & 0.125752 & AZACITADINE (Vidaza) & 34 & 0.008748 & 0.437397 & EOX & 16 & 0.02515 & 0.737015 & PEMETREXED & 46 \\
\hline 0.008748 & 0.1345 & BENDAMUSTINE HCL & 16 & 0.00328 & 0.440678 & EPIRUBICIN & 6 & 0.002187 & 0.739202 & PLATELET & 4 \\
\hline 0.007108 & 0.141607 & BEP & 13 & 0.066703 & 0.507381 & ETOPOSIDE & 122 & 0.009841 & 0.749043 & R-CHOP & \\
\hline 0.00164 & 0.143248 & $\mathrm{BEVAC} / \mathrm{CAPEC}$ & 3 & 0.02187 & 0.529251 & $\mathrm{FC}$ & 40 & 0.001093 & 0.750137 & R-CVP & \\
\hline 0.009295 & 0.152542 & BEVACIZUMAB & 17 & 0.011482 & 0.540733 & FCR & 21 & 0.002187 & 0.752324 & R-EPOCH & 4 \\
\hline 0.000547 & 0.153089 & & 1 & & 0.542373 & FERRLECIT & 3 & 0.00164 & 0.753964 & R-ESHAP & 3 \\
\hline 0.017496 & 0.170585 & CARB & 32 & 0.004921 & 0.547294 & FOLFIRI/OX & 9 & 0.002187 & 0.756151 & RICE & 4 \\
\hline 10388 & 0.180973 & CARI & 19 & 0.011482 & 0.558775 & & 21 & 0.021323 & 0.777474 & RITUX/B & 39 \\
\hline 0.009295 & 0.190268 & CARB & 17 & 24 & 0.5883 & GEMCITABINE HCL & 54 & 0547 & 0.778021 & CYCLOS & 1 \\
\hline & 0.235648 & & 83 & & & & 16 & & 0.781301 & $\mathrm{DA} / \mathrm{CYCLO}$ & 6 \\
\hline & 0.240569 & I/BEVAC & 9 & & & & & & & $\mathrm{C}$ & 1 \\
\hline & 0.249863 & EMET & 17 & & & & 10 & & 225 & & 30 \\
\hline & 0.268453 & & 34 & & & & & & & PAMID & \\
\hline & 0.26 & & 1 & & & & 24 & & & ZOMET & \\
\hline & 0.2875 & & 34 & & & & 5 & & & & \\
\hline 12575 & 0.30 & & 23 & & & & 10 & & & & 47 \\
\hline 0.003827 & 0.303991 & & 7 & & & IVIG-GAMMUNEX & 8 & 0.098414 & & ZOMETA & 180 \\
\hline 0.004374 & 0.308365 & CISPL/PEMET & 8 & 0.00164 & 0.632039 & IXABEPLIONE & 3 & & & & \\
\hline
\end{tabular}

Table 4. Average infusion length for each chemotherapy regimen (h:mm) based on industry standards and clinic nursing staff input.

\begin{tabular}{|c|c|c|c|c|c|}
\hline Regimen & Infusion Time & Regimen & Infusion Time & Regimen & Infusion Time \\
\hline $0.45 \mathrm{NSS}$ & $0: 30$ & CISPLATIN & $4: 00$ & Magnesium 1 gram & $1: 00$ \\
\hline $0.9 \mathrm{NSS}$ & 1:00 & CISPLATIN $>75 \mathrm{MG} / \mathrm{M} 2$ & 4:00 & OXALI/BEVAC & 3:00 \\
\hline 1 UUNIT BLOOD & $1: 30$ & CYCLO/DOXOR & $1: 20$ & OXALI/BEVAC 1st dose & $3: 30$ \\
\hline 2 UNITS BLOOD & 3:00 & CYCLO/VELC & $1: 10$ & OXALIPLATIN & 2:00 \\
\hline 2 UNITS BLOOD + PLATELET & $3: 30$ & DECITABINE & 1:00 & PACLI/CARBO & $3: 30$ \\
\hline 5 -FU & 2:00 & DOCET/HERCE/PETUZ & 3:00 & PACLITAXEL & 3:00 \\
\hline ABVD & $0: 55$ & DOCET/ZOMET & $1: 15$ & PAMIDRONATE $>60 \mathrm{~mm}$ & $1: 30$ \\
\hline ADO-TRASTUZUMAB EMTANSINE & $0: 30$ & DOCETAXEL & 1:00 & PANIT/IRINO & $2: 30$ \\
\hline Ancillary Therapy & $0: 20$ & DOXORUBICIN HCL & $0: 20$ & PANITUMUMAB & 3:00 \\
\hline AZACITADINE (Vidaza) & 0:05 & EOX & $2: 20$ & PEMETREXED & $0: 10$ \\
\hline BENDAMUSTINE HCL & 1:00 & EPIRUBICIN & $0: 20$ & PLATELET & $0: 20$ \\
\hline $\mathrm{BEP}$ & 5:00 & ETOPOSIDE & 1:00 & $\mathrm{R}-\mathrm{CHOP}$ & 6:00 \\
\hline BEVAC/CAPEC & $1: 30$ & $\mathrm{FC}$ & $1: 30$ & R-CVP & $6: 00$ \\
\hline BEVACIZUMAB & $1: 30$ & FCR & 5:00 & R-EPOCH & 8:00 \\
\hline BLEOMYCIN & 1:05 & FERRLECIT & 1:00 & R-ESHAP & 6:00 \\
\hline CARBO/DOCET & $1: 30$ & FOLFIRI/OX & $5: 40$ & RICE & 5:00 \\
\hline CARBO/ETOPO & $1: 30$ & FOLFOX & $0: 10$ & RITUX/BENDA & 5:00 \\
\hline CARBO/IRINO & 2:00 & GEMCITABINE HCL & $0: 30$ & RITUX/CYCLOS & $5: 30$ \\
\hline CARBO/PACLI & $3: 30$ & HERCEPTIN & 1:00 & RITUX/FLUDA/CYCLO & $6: 30$ \\
\hline CARBO/PACLI/BEVAC & $4: 30$ & IFOSF/DOXOR & 2:00 & RITUX/VELC & $1: 10$ \\
\hline CARBO/PEMET & $1: 10$ & IRINO/BEVAC & $2: 30$ & RITUXAN & 4:00 \\
\hline CARFILZOMIB & $1: 40$ & IRINO/PANIT & 4:30 & VELCA/PAMID & $1: 35$ \\
\hline CISPL/5-FU & 4:00 & IRINOTECAN HCL & $1: 30$ & VELCA/ZOMET & $0: 17$ \\
\hline CISPL/DOCET & 5:00 & IRON DEXTRAN & $7: 40$ & VELCADE & 0:05 \\
\hline CISPL/ETOPO & 5:00 & IV Medication & 1:00 & VENOFER & 2:00 \\
\hline CISPL/GEMCI & $4: 30$ & IVIG-GAMMUNEX & 4:00 & ZOMETA & $0: 15$ \\
\hline CISPL/PEMET & $4: 10$ & IXABEPLIONE & 3:00 & & \\
\hline
\end{tabular}

FCR/FC regimen will have labs drawn on the first day of treatment when they receive FCR, but on days two and three the patient will come straight back to the infusion clinic and the nurses will give the pharmacy their chemotherapy order. In this example, the probability of needing labs for FCR is 1 and the probability of needing labs for FC is 0. Similarly, for a five day treatment such as Decitabine, a patient will only have labs drawn on $20 \%$ of their visits. Table 3 summarizes the empirical distribution of infusions and Slocum (2014) provides the probability of labs for all chemotherapy regimens administered in the last year. Table 4 lists the average infusion length for each chemotherapy regimen.

Due to patients with consecutive days of treatment, each day is not independent from the previous day. Since this model only simulates one day at a time, it was important to include the probability of a patient requiring labs in order to account for the impact multiday patients have on the system. These patients are typically the first to have their pharmacy orders placed because they are able to bypass the lab phase and their chemotherapy orders are on hand from the previous day. If the model assumed patients always required labs, the pharmacy would rarely receive orders before 9:00 $\mathrm{AM}$, which is unrealistic. 


\subsection{Verification and Validation}

Multiple staff members reviewed the model logic; further, the nurses, pharmacists, and doctors all agreed some rare occurrences should be omitted from the model such as appointment no-shows and adverse reactions to infusions.

We used several statistics to validate the simulation to include number of patients treated, wait time statistics, processing times, and historical overtime data. Using 20 replications of 7,500 iterations, the model treated an average of 13.7 patients per day which matches the historical throughput while the minimum (7) and maximum (21) are consistent with the clinic's historical records. The processing times for lab results and the pharmacy match the anecdotal times presented by the nursing staff and pharmacists. Personal observations of the clinic confirm the simulation's backlog of chemotherapy orders at the data entry process is very indicative of true behavior. Interested readers should see Slocum (2014) for more validation details.

\subsection{Approach}

After considering several simulation software packages, we chose to implement the simulation in a combination of Microsoft Excel and Visual Basic for Applications (VBA) for several reasons. The most important factor was the administrators' high comfort level and familiarity with the software. Using software they had experience with in other clinic solutions maximized their ability to manipulate and display simulation results themselves.

The VBA source code comprises four major modules:

- Patient Creation,

- Base Schedule,

- Proposed Schedule, and

- Loop Construction/Main Menu.

Slocum (2014, pp. 26-30) develops the model in detail with pseudocode snippets for various processes. The entire source code for each module is available from (Slocum 2014, App. E). The simulation interface was specifically designed to compare the baseline schedule to a proposed schedule. An example of one MS Excel output is included in the Appendix as Figure A1.

We chose to use 20 replications of 7,500 iteration after pilot simulations of each schedule for 2,500 and 5,000 iterations provided nearly identical results but did not sufficiently capture the tails of the patient distribution. Further, there were concerns over computation time in order to be able to work in near-real time with stakeholders from the Durham VA clinic. Using these settings produced results quickly on their machines as well.

Since the clinic's current policy (base case) is a trivial block schedule with $k=1$ blocks, we first consider a selection of reasonable two block schedules for simulation and testing. We also assess performance of select three block schedules. VAMC staff assisted with developing the criteria for a "reasonable" policy which emphasized simplicity and ease of implementation - these criteria greatly reduced the possible schedules to be tested. Table 5 summarizes the simulation inputs of interest. 
Table 5. Required inputs to simulate proposed schedule. These were the decisions available to the chemotherapy clinic.

\begin{tabular}{ll} 
Simulation Inputs & Description \\
\hline Number of Schedule Blocks $(k)$ & Number of appointment slots to use \\
$k$ Appointment Times & Example $(k=3): 8$ AM, 10 AM, 12 PM \\
Patient Population (if $k=2)$ & Patients to assign to first appointment
\end{tabular}

\section{Results}

Based on VAMC nursing staff inputs, this study examined two scheduling policies that met the ease of implementation criterion. The results below were obtained using the method of synchronized common random numbers such that the patients who would arrive early (late) to the first appointment block arrive equally early (late) to the subsequent appointments tested (Law, 2007). Each schedule was simulated for 7,500 iterations.

The first policy was a fixed-block scheduling approach with two blocks. This would be easiest to implement but potentially challenging to adequately shape patient arrivals into only two appointment slots. The second option tested was a three fixedblock policy which provides the clinic with greater flexibility and control in assigning appointment times.

\subsection{Two Appointment Policies}

The two appointment policy categorized patients based on their chemotherapy regimen's expected infusion length and assigned them to one of two potential appointment times. The first appointment time remained at 8:00 AM. Key performance drivers were the patient population and the appointment time.

The patient population refers to the patients (or chemotherapy regimens) that received an alternate appointment time. For example, if the patient population was 60 minutes, then all patients whose infusions are less than or equal to 60 minutes were given the second appointment time. This second appointment time ranged from 8:00 $\mathrm{AM}$ to 4:00 PM. If the second appointment time was too close to 8:00 AM, there is little change from the base schedule; if the appointment time was too late in the afternoon, nurse overtime increases.

The simulation tested patient population cutoffs of $30,60,90$, and 120 minutes which comprise $32,49,61$, and 71 percent of the total patient population, respectively. The appointment times evaluated ranged in 30 minute increments from 10:30 AM to 1:00 PM. This results in the schedules that are combinations of Table 6. For example, the (3-2) schedule assigns patients with infusions 90 minutes or shorter an 11:00 AM appointment time (patients with infusions greater than 90 minutes receive the 8:00 AM appointment). Figure 2 illustrates the average performance for these two appointment policies.

From Figure 3 it is clear schedules 2-2 and 3-2 are statistically indistinguishable with 3-1 being the best schedule to minimize overtime and 2-3 best for reducing patient wait times. This illustrates the tradeoff between performance metrics and greatly simplifies the decision space. For reference, all two appointment schedule results are in Appendix B, Table B1. 
Table 6. Two Appointment Schedules tested; schedules are named $(i-j)$ for reference. Empirical distribution of patient population provided (e.g., $67 \%$ of patients require an infusion that is 90 minutes or less).

\begin{tabular}{lll||rc}
\hline Patient Population Index $(i)$ & Patient Population & Percent of Patients & Appointment Index $(j)$ & Appointment Time \\
\hline 1 & 30 minutes & $32 \%$ & 1 & $10: 30$ AM \\
2 & 60 minutes & $49 \%$ & 2 & $11: 00 \mathrm{AM}$ \\
3 & 90 minutes & $67 \%$ & 3 & $11: 30 \mathrm{AM}$ \\
4 & 120 minutes & $71 \%$ & 4 & $12: 00 \mathrm{PM}$ \\
& & & 5 & $12: 30 \mathrm{PM}$ \\
& & & 6 & $1: 00 \mathrm{PM}$ \\
\hline
\end{tabular}
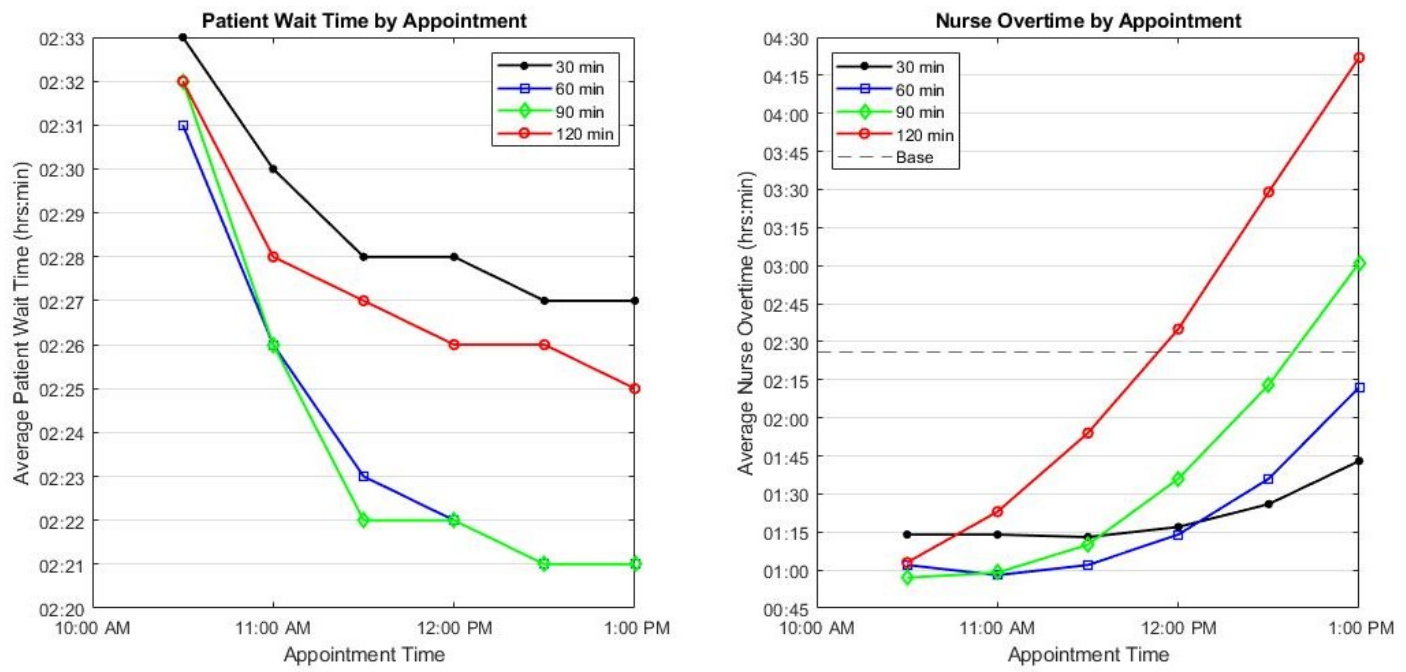

Figure 2. (color online) Average performance of proposed two appointment policies. Note the different axis scales for patient waiting time (left) and nurse overtime (right); the base case for patient wait times is 3:05 (off chart), the base case for nurse overtime is $2: 26$. 


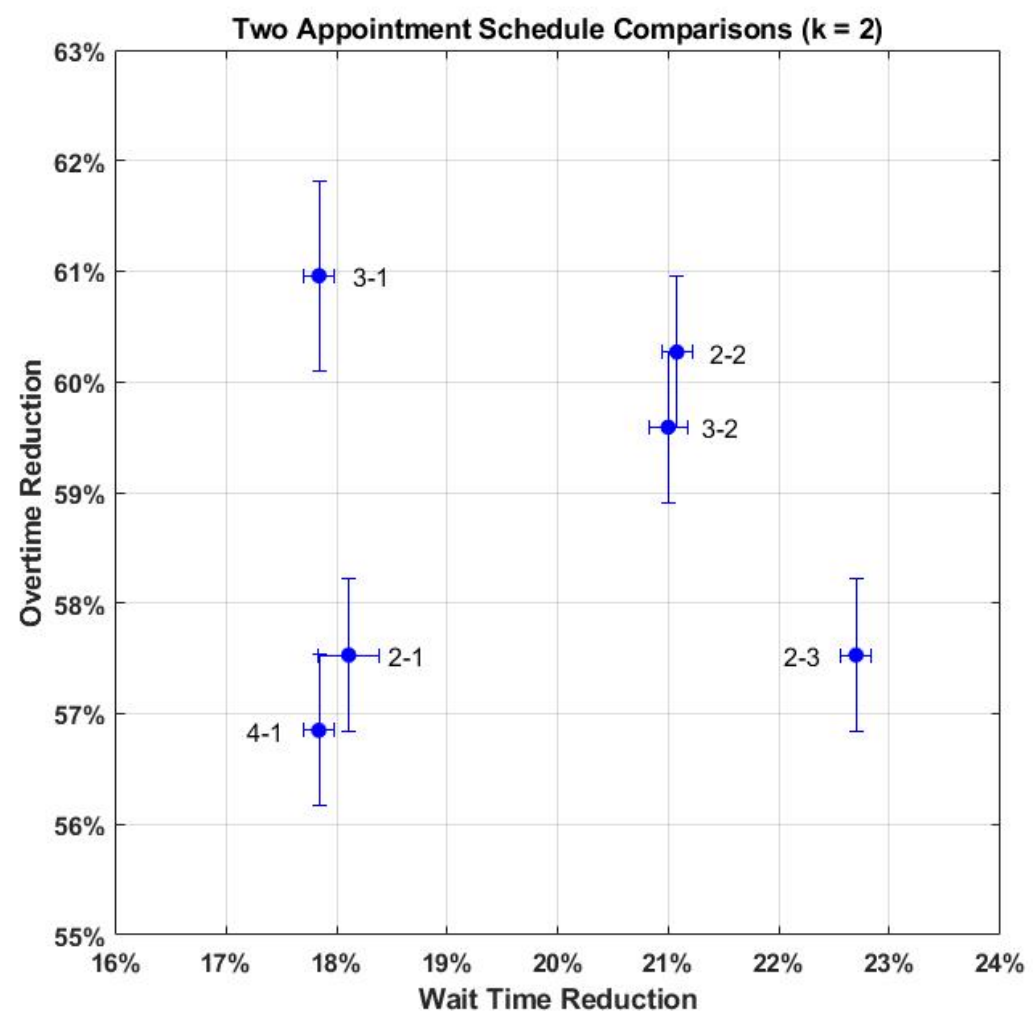

Figure 3. Comparison of best two appointment schedules $(k=2)$ with $95 \%$ confidence intervals for mean performance. 
Table 7. Three Appointment Schedules tested where $T_{\text {Infusion }}$ is the infusion length in minutes

\begin{tabular}{llll}
\hline Schedule Name & $\begin{array}{l}\text { 1st Appointment } \\
T_{\text {Infusion }} \geq 120 \mathrm{~min}\end{array}$ & $\begin{array}{l}\text { 2nd Appointment } \\
30<T_{\text {Infusion }} \leq 120 \mathrm{~min}\end{array}$ & $\begin{array}{l}\text { 3rd Appointment } \\
T_{\text {Infusion }} \leq 30 \mathrm{~min}\end{array}$ \\
\hline 1 & $8: 00 \mathrm{AM}$ & $9: 30 \mathrm{AM}$ & $11: 00 \mathrm{AM}$ \\
2 & $8: 00 \mathrm{AM}$ & $9: 30 \mathrm{AM}$ & $11: 30 \mathrm{AM}$ \\
3 & $8: 00 \mathrm{AM}$ & $10: 00 \mathrm{AM}$ & $11: 30 \mathrm{AM}$ \\
4 & $8: 00 \mathrm{AM}$ & $10: 00 \mathrm{AM}$ & $12: 00 \mathrm{PM}$ \\
5 & $8: 00 \mathrm{AM}$ & $10: 30 \mathrm{AM}$ & $12: 00 \mathrm{PM}$ \\
6 & $8: 00 \mathrm{AM}$ & $10: 30 \mathrm{AM}$ & $12: 30 \mathrm{PM}$ \\
\hline
\end{tabular}

\subsection{Three Appointment Policies}

The two appointment policy is the simplest to implement but exploring the impact of a three appointment policy provides insights to understand the tradeoffs between scheduling complexity and key performance metrics. From the results in Section 4.1. the best policies shared two traits: the patient populations were evenly distributed across the appointment times and the fixed intervals were sufficiently spread out. Note that although small fixed intervals continue to reduce overtime, they unnecessarily increase patient waiting times. The interested reader can consult (Slocum, 2014, Ch. 5 ) for a more detailed discussion of fixed interval selection. We chose to group patients into three groups based on infusion lengths less than or equal to 30 minutes, more than 30 but less than or equal to 120 minutes, and longer than 120 minutes. These three groups account for 32,36 , and 32 percent of the total population respectively. Because Section 4.1 shows that regardless of patient population, appointment times after 12:30 PM increase average overtime in the clinic, we constructed the schedules in Table 7 .

Figure 4 demonstrates schedules 4 and 5 are dominant. Though statistically indistinguishable, schedule 4's even two hour spacing between appointment times may be more intuitive for nurses, patients, and administrators. Schedule 4 outperforms the best $k=2$ schedule by $6 \%$ in overtime and $3 \%$ in wait time reduction. All results for three appointment schedules are in Appendix B, Table B2.

\subsection{Discussion}

As an example of how these policies affect clinic performance metrics, Figure 5 provides a visual summary of a 17 patient example with their infusion times labeled in minutes. The top example illustrates the clinic's current policy. Notice the various infusions categories are widely intermixed and the longest treatments were processed 9th, 10th, and 17th. By failing to sequence these longer infusions earlier in the schedule, the clinic worked 3.7 hours of overtime. The best two appointment schedule from Section 4.1 makes a visible difference to the same patient list resulting in a schedule with zero overtime hours and the last patient infusion concluding at 3:59 PM. After applying the best schedule from Section 4.2 , the long and intermediate infusions are clearly grouped first. This schedule achieves zero overtime with the final infusion complete at 3:52 PM. Table 8 summarizes performance measures for the example in Figure 5 .

One practical solution to cope with variability in the lab process is to stagger appointment times to break up the massive influx of pharmacy orders between 9:00-10:30 


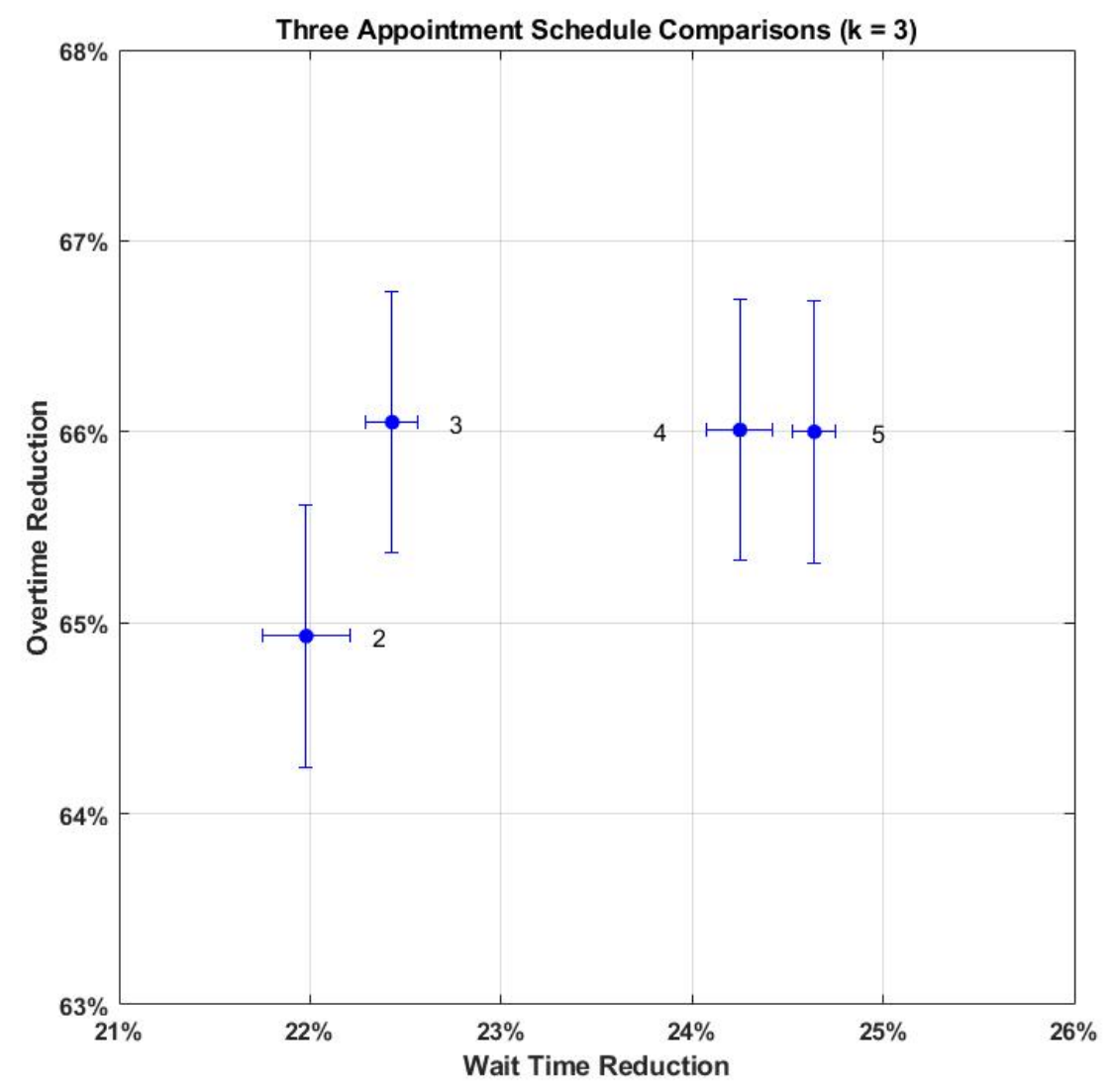

Figure 4. Comparison of best three appointment schedules $(k=3)$ with $95 \%$ confidence intervals for mean performance.

\begin{tabular}{|c|c|c|c|c|c|c|c|c|c|c|c|c|c|c|c|c|}
\hline \multicolumn{17}{|c|}{ Sequence of Chemotherapy Orders in to the Pharmacy } \\
\hline 1 & 2 & 3 & 4 & 5 & 6 & 7 & 8 & 9 & 10 & 11 & 12 & 13 & 14 & 15 & 16 & 17 \\
\hline$k=1 \lcm{60}$ & 90 & 90 & 100 & 70 & 140 & 120 & 20 & 240 & 240 & 95 & 120 & 90 & 17 & 210 & 10 & 240 \\
\hline 1 & 2 & 3 & 4 & 5 & 6 & 7 & 8 & 9 & 10 & 11 & 12 & 13 & 14 & 15 & 16 & 17 \\
\hline$k=2 \quad 100$ & 140 & 120 & 240 & 95 & 240 & 210 & 240 & 120 & 90 & 70 & 20 & 60 & 90 & 10 & 90 & 17 \\
\hline 1 & 2 & 3 & 4 & 5 & 6 & 7 & 8 & 9 & 10 & 11 & 12 & 13 & 14 & 15 & 16 & 17 \\
\hline$k=3 \quad 140$ & 240 & 240 & 210 & 240 & 90 & 100 & 120 & 70 & 95 & 60 & 90 & 90 & 120 & 20 & 10 & 17 \\
\hline quick & $t \leq$ & & she & & $60<$ & $t \leq 1$ & & & rmed & & 120 & $k t<$ & 240 & & $t \geq$ & \\
\hline
\end{tabular}

Figure 5. (color online) Pharmacy sequences for single appointment (top), two appointments (middle), and three appointments (bottom) with infusion times in minutes 
Table 8. Performance measures from example in Figure 5

\begin{tabular}{lll}
\hline Number of Appointments $(k)$ & Average Number of Orders in Pharmacy Queue & Average Waiting Time (h:mm) \\
\hline$k=1$ & 4.6 & $3: 28$ \\
$k=2$ & 2.2 & $2: 26$ \\
$k=3$ & 1.4 & $2: 13$ \\
\hline
\end{tabular}

AM. The two and three appointment policies reduce average waiting time in the clinic predominantly by spreading out chemotherapy orders. In the example shown in Figure 5. the average queue length varied greatly between the three policies. As the number of appointment blocks increases, the average number of orders will decrease until a lowerbound. Due to the variability in the lab process, this lowerbound is unlikely to be zero. For a more detailed discussion of model results, the reader is encouraged to consult (Slocum, 2014, Ch. 5-6).

\section{Conclusion}

This study examined two scheduling policies that can be easily implemented at the Durham VAMC chemotherapy clinic. The best two appointment policy assigns all patients infusions taking less than 1 hour an appointment time of 11:00 AM (recall the rest are scheduled for 8:00 AM). This schedule reduced the average waiting time in the clinic by $21 \%$ and reduced average nurse overtime by $60 \%$.

With three appointments, the best policy assigns 12:00 PM appointments for patients with infusion lengths less than or equal to 30 minutes, 10:00 AM appointments for patients with infusion lengths of 31-120 minutes, and 8:00 AM appointments for patients with infusions longer than 120 minutes. This schedule reduced the average waiting time in the clinic by $24 \%$ and the average overtime by $66 \%$.

To minimize overtime costs, the optimal scheduling solution appears to prioritize patients according to a Longest Infusion Time (LIT) heuristic. This may not always be practical based on constant appointment changes, additions, and uncertain daily patient volume until the day of treatment. However, chemotherapy clinics can used standardized fixed-block scheduling techniques to shape the patient arrivals such that the longest infusion times arrive first and the shortest infusion times arrive last. Increasing the number of blocks moves the schedule close to the LIT order but at the cost of increased complexity.

VA and community hospitals that treat a high volume of Medicaid or Medicare patients may have little incentive to change their current practices (U.S. Centers for Medicare \& Medicaid Services, 2019a, 2019b). Generally speaking, they do not have to compete for business and their monetary compensation for treatment is low, therefore providers may be largely indifferent to patient waiting times. But as the population of veterans from over a decade of war, access to healthcare increases as a result of the Affordable Care Act (U.S. 111th Congress, 2010), and oncology treatment protocols increase patient life expectancies, the demand for chemotherapy services will likely outpace supply. Administrators would be well-served by applying cost-free solutions, like good scheduling, to reduce operating costs and improve patient care. 


\section{Disclaimer}

The views expressed in this paper are those of the authors and do not reflect the official policy or position of the United States Army, the Department of Defense, the Department of Veterans Affairs, or the United States Government.

\section{Acknowledgements}

This paper would not have been possible without the nurses at the Durham VAMC infusion clinic whose patience and willingness to share their expertise supported every aspect of this project. The fourth author was supported by a grant from the U.S. Army Research Office (grant \# W911NF1910055).

\section{References}

Abo-Hamad, W., \& Arisha, A. (2013). Simulation-based framework to improve patient experience in an emergency department. European Journal of Operational Research, 224(1), $154-166$.

Ahmed, Z., ElMekkawy, T., \& Bates, S. (2011). Developing an efficient scheduling template of a chemotherapy treatment unit: A case study. Australasian Medical Journal, 4(10), $575-588$.

Alvarado, M., Cotton, T., Ntaimo, L., Pérez, E., \& Carpentier, W. (2018). Modeling and simulation of oncology clinic operations in discrete event system specification. Simulation, 94 (2), 105-121.

Babashov, V., Aivas, I., Begen, M., Cao, J., Rodrigues, G., D’Souza, D., \& Lock, M. (2017). Reducing patient waiting times for radiation therapy and improving the treatment planning process: a discrete-event simulation model (radition treatment planning). Clinical Oncology, $29(6), 385-391$.

Belter, D., Hasley, J., Severtson, H., Fix, A., Michelfelder, L., Michalak, K., \& Abella, P. (2012). Evaluation of outpatient oncology services using lean methodology. Oncology Nursing Forum, 39(2), 136-140.

Cayirli, T., \& Veral, H. (2003). Outpatient scheduling in health care: A review of literature. Production and Operations Management, 12(4), 519-549.

Chabot, G., \& Fox, M. (2005). The creation of a patient-classification system in an outpatient infusion center setting. Oncology Nursing Forum, 32(3), 535-538.

Delaney, B., Jalaludin, B., Moylan, E., \& Barton, M. (2002). The Development of a Model of Outpatient Chemotherapy Delivery —Chemotherapy Basic Treatment Equivalent (CBTE). Clinical Oncology, 14(5), 406-412.

Demir, E., Southern, D., Verner, A., \& Amoaku, W. (2018). A simulation tool for better management of retinal services. BMC Health Services Research, 18(1), 759-766.

Eisenburg, S. (2009). Ambulatory oncology clinics: Oncology nurses juggle staffing and scheduling in the outpatient setting. ONS Connect, 24(8), 6-8.

Garaix, T., Rostami, S., \& Xie, X. (2018). Daily outpatient chemotherapy appointment scheduling with random deferrals. Flexible Services and Manufacturing Journal, 1-25. (published online 21 Sep 2018)

Gul, M., \& Guneri, A. (2015). A comprehensive review of emergency department simulation applications for normal and disaster conditions. Computers $\mathcal{E}$ Industrial Engineering, 83, $327-344$.

Gul, M., Guneri, A., \& Gunal, M. (2019). Emergency department network under disaster conditions: The case of the possible major Instanbul earthquake. Journal of the Operational Research Society, 1-15. 
Gupta, D., \& Denton, B. (2008). Appointment scheduling in health care: Challenge and opportunities. IIE Transactions, 40(9), 800-819.

Hendershot, E., Murphy, C., Doyle, S., Van-Clieaf, J., Lowry, J., \& Honeyford, L. (2005). Outpatient chemotherapy administration: Decreasing wait times for patients and families. Journal of Pediatric Oncology Nursing, 22(1), 31-37.

Hesaraki, A., Dellaert, N., \& de Kok, T. (2019). Generating outpatient chemotherapy appointment templates with balanced flowtime and makespan. European Journal of Operational Research, $275(1), 304-318$.

Kadri, F., Chaabane, S., \& Tahon, C. (2014). A simulation-based decision support system to prevent and predict strain situations in emergency department systems. Simulation Modelling Practice and Theory, 42, 32-52.

Kallen, M., Terrell, J., Lewis-Patterson, P., \& Hwang, J. (2012). Improving wait time for chemotherapy in an outpatient clinic at a comprehensive cancer center. Journal of Oncology Practice, 8(1), e1-e7.

Kuhl, M., Ivy, J., Lada, E., Steiger, N., Wagner, M., \& Wilson, J. (2010). Univariate input models for stochastic simulation. Journal of Simulation, 4(2), 81-97.

Law, A. (2007). Simulation modeling and analysis (4th ed.). Boston, MA: McGraw-Hill. (pp. $578-593)$

Liang, B., Turkcan, A., Ceyhan, M., \& Stuart, K. (2015). Improvement of chemotherapy patient flow and scheduling in an outpatient oncology clinic. International Journal of Production Research, 53(24), 7177-7190.

Oh, C., Novotny, A., Carter, P., Ready, R., \& Campbell, D. (2016). Use of a simulation-based decision support tool to improve emergency department throughput. Operations Research for Health Care, 9, 29-39.

Ordu, M., Demir, E., \& Fofallis, C. (2019). A decision support system for demand and capacity modelling of an accident and emergency department. Health Systems, 1-26. (Published online 6 Jan 2019)

Richardson, D., \& Cohn, A. (2018). Modeling the impact of make-ahead chemotherapy drug policies through discrete event simulation. In M. Rabe, A. Juan, N. Mustafee, A. Skoogh, S. Jain, \& B. Johansson (Eds.), Proceedings of the 2018 Winter Simulation Conference (pp. 2690-2700).

Rohleder, T., Lewkonia, P., Bischak, D., Duffy, P., \& Hendijani, R. (2011). Using simulation modeling to improve patient flow at an outpatient orthodpedic clinic. Health Care Management Science, 14(2), 135-145.

Seminelli, M., Wilson, J., \& McConnell, B. (2016). Implementing discrete event simulation to improve optometry clinic operations. In T. Roeder, P. Frazier, R. Szechtman, E. Zhou, T. Huschka, \& S. Chick (Eds.), Proceedings of the 2016 Winter Simulation Conference (pp. 2157-2168).

Slocum, R. (2014). Improving Chemotherapy Infusion Operations through the Simulation of Scheduling Heuristics. (Masters thesis, Operations Research Graduate Program, North Carolina State University, http://www.lib.ncsu.edu/resolver/1840.16/9276)

Suss, S., Bhuiyan, N., Demirli, K., \& Batist, G. (2017). Toward implementing patient flow in a cancer treatment center to reduce patient waiting time and improve efficiency. Journal of Oncology Practice, 13(6), 383, e530-e537.

Thomas, S., Glynne-Jones, R., \& Chait, I. (1997). Is it worth the wait? A survey of patients' satisfaction with an oncology outpatient clinic. European Journal of Cancer Care, 6(1), 50-58.

Turkcan, A., Zeng, B., \& Lawley, M. (2012). Chemotherapy operations planning and scheduling. IIE Transactions on Healthcare Systems Engineering, 2(1), 31-49.

U.S. 111th Congress. (2010). The Patient Protection and Affordable Care Act (H.R. 3590). (Accessed 31 Oct 2019, https://www.govinfo.gov/app/details/BILLS-111hr3590enr.)

U.S. Centers for Medicare \& Medicaid Services. (2019a). Medicaid.gov. (Accessed 31 Oct 2019, https://www.medicaid.gov/.)

U.S. Centers for Medicare \& Medicaid Services. (2019b). Medicare.gov. (Accessed 31 Oct 
2019, https://www.medicare.gov.)

U.S. Department of Veterans Affairs. (2018a). Durham VA Health Care System website. (Accessed 16 July 2018, https://www.durham.va.gov)

U.S. Department of Veterans Affairs. (2018b). History - Department of Veterans Affairs (VA). (Accessed 31 Oct 2019, https://www.va.gov/about_va/vahistory.asp)

U.S. Department of Veterans Affairs. (2018c). VA History In Brief. (https://www.va.gov/ opa/publications/archives/docs/history_in_brief.pdf, 12)

Welch, J., \& Bailey, N. (1952). Appointment systems in hospital outpatient departments. The Lancet, 259 (6718), 1105-1108.

Williamson, T. (2008). The shift of oncology inpatient care to outpatient care: The challenge of retaining expert oncology nurses. Clinical Journal of Oncology Nursing, 12(2), 186-189.

Woodall, J., Gosselin, T., Boswell, A., Murr, M., \& Denton, B. (2013). Improving patient access to chemotherapy treatment at Duke Cancer Institute. Interfaces, 43(5), 449-461.

Yokouchi, M., Aoki, S., Sang, H., Zhao, R., \& Takakuwa, S. (2012). Operations analysis and appointment scheduling for an outpatient chemotherapy department. In C. Laroque, J. Himmelspach, R. Pasupathy, O. Rose, \& A. Uhrmacher (Eds.), Proceedings of the 2012 Winter Simulation Conference (pp. 1-12).

\section{ORCID iD}

Herbert L. Jones (iD https://orcid.org/0000-0003-4512-1159

Matthew T. Fletcher iD https://orcid.org/0000-0002-4138-4245

Brandon M. McConnell (iD) https://orcid.org/0000-0003-0091-215X

Thom J. Hodgson (iD https://orcid.org/0000-0002-8077-4780

James R. Wilson (iD https://orcid.org/0000-0002-6255-4485

\section{Appendix A. Sample Output}

\begin{tabular}{|c|c|}
\hline \multicolumn{2}{|c|}{ Base Schedule } \\
\hline Nurses & 4 \\
\hline Patients & 14 \\
\hline \multicolumn{2}{|l|}{ Infusion Data } \\
\hline 0-1 HR & 6 \\
\hline 1-2 HR & 2 \\
\hline $2-4 \mathrm{HR}$ & 3 \\
\hline$>4 \mathrm{HR}$ & 2 \\
\hline Avg. Wait Time & $3: 07$ \\
\hline Wait on Lab & 1:09 \\
\hline Wait on Pharmacy & $1: 33$ \\
\hline Overtime hours & $2: 34$ \\
\hline
\end{tabular}

\begin{tabular}{|l|r|}
\hline \multicolumn{2}{|c|}{ Proposed Schedule } \\
\hline Nurses & 4 \\
\hline Patients & 14 \\
\hline Infusion Data \\
\hline \multicolumn{2}{|c|}{ 0-1 HR } \\
\hline \multicolumn{2}{|c|}{ 1-2 HR } \\
\hline \multicolumn{2}{|c|}{-4 HR } \\
\hline > 4 HR \\
\hline Avg. Wait Time \\
\hline Wait on Lab \\
\hline Wait on Pharmacy \\
\hline \multicolumn{2}{|c|}{$2: 27$} \\
\hline Overtime hours & $1: 05$ \\
\hline
\end{tabular}

Figure A1. Example of Simulation Output Table for a proposed schedule (right) as compared to the base schedule (left). In this scenario, the number of nurses, patients, and the required infusions are identical for appropriate comparison. Simulation results include average wait time, delays at the lab and pharmacy, and the number of nurse overtime hours. 


\section{Appendix B. Simulation Results}

Table B1. Simulation results for all two appointment schedules. The mean patient wait times and nurse overtime results reported in "hours:minutes" format. The '\% Reduction' column denotes the percent reduction in customer wait time (left) and nurse overtime (right); negative values indicate an increase. Lower and upper endpoints for the $95 \%$ confidence interval for the mean also provided in the "hours:minutes" format.

\begin{tabular}{|c|c|c|c|c|c|c|c|c|c|c|}
\hline $\mathrm{i}-\mathrm{j}$ & Patient Pop. (min) & Appt Time & Wait Time & $\%$ Reduction & Lower & Upper & Overtime & $\%$ Reduction & Lower & Upper \\
\hline Base & All & $8: 00$ & $3: 05$ & & & & $2: 26$ & & & \\
\hline $1-1$ & 30 & $10: 30$ & $2: 33$ & $17.30 \%$ & $2: 32$ & $2: 33$ & $1: 14$ & $49.32 \%$ & $1: 12$ & $1: 17$ \\
\hline $1-2$ & 30 & $11: 00$ & $2: 30$ & $18.40 \%$ & $2: 29$ & $2: 30$ & $1: 14$ & $49.32 \%$ & $1: 12$ & $1: 17$ \\
\hline $1-3$ & 30 & $11: 30$ & $2: 28$ & $20.00 \%$ & $2: 28$ & $2: 29$ & $1: 13$ & $50.00 \%$ & $1: 11$ & $1: 16$ \\
\hline $1-4$ & 30 & $12: 00$ & $2: 28$ & $19.53 \%$ & $2: 27$ & $2: 28$ & $1: 17$ & $47.26 \%$ & $1: 14$ & $1: 19$ \\
\hline $1-5$ & 30 & $12: 30$ & $2: 27$ & $20.54 \%$ & $2: 27$ & $2: 28$ & $1: 26$ & $41.10 \%$ & $1: 24$ & $1: 29$ \\
\hline $1-6$ & 30 & $13: 00$ & $2: 27$ & $20.54 \%$ & $2: 27$ & $2: 28$ & $1: 43$ & $29.45 \%$ & $1: 41$ & $1: 45$ \\
\hline $2-1$ & 60 & $10: 30$ & $2: 31$ & $18.11 \%$ & $2: 30$ & $2: 32$ & $1: 02$ & $57.53 \%$ & $1: 00$ & $1: 04$ \\
\hline $2-2$ & 60 & $11: 00$ & $2: 26$ & $21.08 \%$ & $2: 26$ & $2: 27$ & $0: 58$ & $60.27 \%$ & 0.56 & $1: 00$ \\
\hline $2-3$ & 60 & $11: 30$ & $2: 23$ & $22.70 \%$ & $2: 22$ & $2: 23$ & 1:02 & $57.53 \%$ & 1.00 & 1:04 \\
\hline $2-4$ & 60 & $12: 00$ & $2: 22$ & $23.24 \%$ & $2: 21$ & $2: 22$ & $1: 14$ & $48.88 \%$ & $1: 12$ & $1: 16$ \\
\hline $2-5$ & 60 & $12: 30$ & $2: 21$ & $23.78 \%$ & $2: 21$ & $2: 21$ & $1: 36$ & $33.80 \%$ & $1: 33$ & $1: 38$ \\
\hline $2-6$ & 60 & $13: 00$ & $2: 21$ & $23.78 \%$ & $2: 21$ & $2: 22$ & $2: 12$ & $9.59 \%$ & $2: 10$ & $2: 14$ \\
\hline $3-1$ & 90 & $10: 30$ & $2: 32$ & $17.84 \%$ & $2: 31$ & $2: 32$ & $0: 57$ & $60.96 \%$ & $0: 54$ & $0: 59$ \\
\hline $3-2$ & 90 & $11: 00$ & $2: 26$ & $21.00 \%$ & $2: 25$ & $2: 26$ & $0: 59$ & $59.59 \%$ & 0.57 & 1:01 \\
\hline $3-3$ & 90 & $11: 30$ & $2: 22$ & $23.24 \%$ & $2: 22$ & $2: 23$ & $1: 10$ & $52.05 \%$ & 1.08 & $1: 12$ \\
\hline $3-4$ & 90 & $12: 00$ & $2: 22$ & $22.80 \%$ & $2: 21$ & $2: 22$ & $1: 36$ & $34.25 \%$ & $1: 34$ & $1: 38$ \\
\hline $3-5$ & 90 & $12: 30$ & $2: 21$ & $23.78 \%$ & $2: 21$ & $2: 22$ & $2: 13$ & $8.90 \%$ & $2: 11$ & $2: 15$ \\
\hline $3-6$ & 90 & $13: 00$ & $2: 21$ & $23.78 \%$ & $2: 21$ & $2: 22$ & $3: 01$ & $-23.97 \%$ & $2: 58$ & $3: 03$ \\
\hline $4-1$ & 120 & $10: 30$ & $2: 32$ & $17.84 \%$ & $2: 32$ & $2: 33$ & 1:03 & $56.85 \%$ & 1:01 & 1:05 \\
\hline $4-2$ & 120 & $11: 00$ & $2: 28$ & $19.67 \%$ & $2: 28$ & $2: 29$ & $1: 23$ & $43.15 \%$ & $1: 21$ & $1: 25$ \\
\hline $4-3$ & 120 & $11: 30$ & $2: 27$ & $20.54 \%$ & $2: 26$ & $2: 27$ & $1: 54$ & $21.92 \%$ & 1.52 & $1: 56$ \\
\hline $4-4$ & 120 & $12: 00$ & $2: 26$ & $20.86 \%$ & $2: 25$ & $2: 26$ & $2: 35$ & $-6.16 \%$ & $2: 33$ & $2: 38$ \\
\hline $4-5$ & 120 & $12: 30$ & $2: 26$ & $20.80 \%$ & $2: 26$ & $2: 26$ & $3: 29$ & $-43.15 \%$ & $3: 26$ & $3: 31$ \\
\hline $4-6$ & 120 & $13: 00$ & $2: 25$ & $21.62 \%$ & $2: 25$ & $2: 26$ & $4: 22$ & $-79.45 \%$ & $4: 19$ & $4: 24$ \\
\hline
\end{tabular}

Table B2. Simulation results for all three appointment schedules. The mean patient wait times and nurse overtime results reported in "hours:minutes" format. The '\% Reduction' column denotes the percent reduction in customer wait time (left) and nurse overtime (right); negative values indicate an increase. Lower and upper endpoints for the $95 \%$ confidence interval for the mean also provided in the "hours:minutes" format.

\begin{tabular}{|c|c|c|c|c|c|c|c|c|c|c|c|}
\hline & 1st Appt & 2nd Appt & 3rd Appt & Wait Time & $\%$ Reduction & Lower & Upper & Overtime & $\%$ Reduction & Lower & Upper \\
\hline Base & $8: 00$ & $\mathrm{n} / \mathrm{a}$ & $\mathrm{n} / \mathrm{a}$ & $3: 05$ & & & & $2: 26$ & & & \\
\hline 1 & $8: 00$ & 09:30 & $11: 30$ & $2: 28$ & $19.71 \%$ & $2: 28$ & $2: 29$ & $0: 53$ & $63.67 \%$ & $0: 50$ & $0: 55$ \\
\hline 2 & $8: 00$ & 09:30 & $11: 30$ & $2: 24$ & $21.98 \%$ & $2: 23$ & $2: 24$ & $0: 51$ & $64.93 \%$ & $0: 49$ & $0: 53$ \\
\hline 3 & $8: 00$ & 10:00 & $11: 30$ & $2: 23$ & $22.43 \%$ & $2: 23$ & $2: 23$ & $0: 49$ & $66.05 \%$ & $0: 47$ & $0: 51$ \\
\hline 4 & $8: 00$ & 10:00 & $12: 00$ & $2: 20$ & $24.25 \%$ & $2: 19$ & $2: 20$ & $0: 49$ & $66.01 \%$ & $0: 47$ & $0: 51$ \\
\hline 5 & $8: 00$ & $10: 30$ & $12: 00$ & $2: 19$ & $24.64 \%$ & $2: 19$ & $2: 19$ & $0: 49$ & $66.00 \%$ & $0: 47$ & $0: 51$ \\
\hline 6 & $8: 00$ & $10: 30$ & $12: 30$ & $2: 16$ & $26.39 \%$ & $2: 15$ & $2: 16$ & $0: 56$ & $61.47 \%$ & $0: 54$ & $0: 58$ \\
\hline
\end{tabular}

